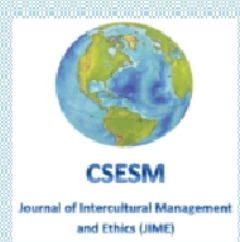

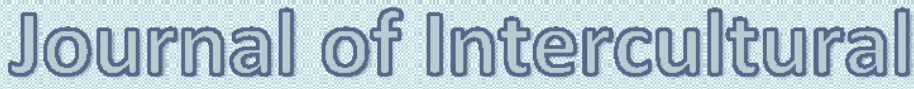

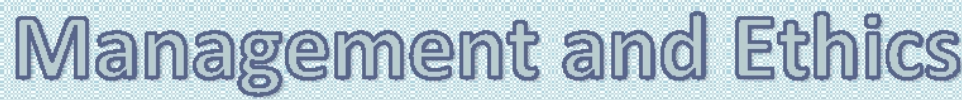

\author{
I0ME
}

ISSN 2601 - 5749, ISSN-L 2601 - 5749

Center for Socio-Economic Studies and Multiculturalism

lasi, Romania

WWW csesmioirg 


\section{TABLE OF CONTENT}

Editorial

Iulian Warter

Where Did Culture Come From? Evolutionary Foundations of Cultural Diversity

Paulo Finuras

Crash: Boeing and the Power of Culture

Thomas D. Zweifel, Vip Vyas

Political Culture, Social Polarization and Electoral Behavior. The Last Decade in Romanian

Political System

Silviu-Petru Grecu

The Principles of Transparency and Judging Others Favorably: The Talmudic View

Hershey H. Friedman, Robert B. Fireworker

Some Issues Regarding the Ethics of the Management at Romanian State-Owned

Companies .55

Baluta Aurelian Virgil, Rada Alexandru Cristian

How Does Logistics Command of the Military Navy Support Local Development and

Cultural Integration?

Rosa Caiazza

Illusion and Disillusion. Case Studies about the Constitution of a New Political Party in

Romania

Alexandru Muraru

How Could We Overcome the Feeling Of Insecurity? Explorations in the Spectrum of Polyscopic Consciousness

Anton Carpinschi

The Employees' Perceptions, Practices and Experiences Regarding the Strategic Process

Carried Out In the Public Hospitals

Ana Niculita 


\title{
HOW DOES LOGISTICS COMMAND OF THE MILITARY NAVY SUPPORT LOCAL DEVELOPMENT AND CULTURAL INTEGRATION?
}

\author{
Rosa Caiazza, $\mathrm{PhD}$ \\ Professor, Parthenope University of Naples, Italy \\ E-mail: rosa.caiazza@uniparthenope.it
}

\begin{abstract}
The Europa Cup 2021 race in Nisida base of Navy Logistics Command (MARICOMLOG) exposed Naples' beauties to all the world. The Commander of Navy base Ammiraglio Comandante Abbamonte and his team gave a huge example of leadership in organizing the sport event, supporting local development, improving cultural integration, and diffusing navy values among civil community. Navy Command worked with local clubs (Italian Naval League of Naples, the Real Yacht Club Savoia) and institutions for managing this international event that have had economic, touristic, cultural effects in supporting local development. With this regatta, the international profile of Naples is strengthened in the panorama of major sporting events linked to the sea.
\end{abstract}

Keywords: management, military navy, strategy

\section{Introduction}

The COVID-19 pandemic has had a deep impact on the sports events. Specific sports were impacted on the base of their accessibility in the lock-down. Outdoor individual sports and home workouts both saw increased participation, while team sports and indoor sports struggled. The impact of the pandemic goes beyond temporary performance accelerating changes that will have long-lasting impacts on sports and events tied to it (Kaplanidou \& Vogt, 2007; Weaver \& Lawton, 2013).

The biggest challenges for the coming year are seen in supply chains and COVID-19related issues, including ongoing challenges relating to physical activity levels, indoor-sport and team-sport participation. The greatest opportunities, meanwhile, are associated with the potential return of large sports events, like the Olympic and Paralympic Games and the ongoing rise in popularity of outdoor and home-based sports. In 2021, the sporting events economy, with the Olympic games, grew up for the first time since the financial crisis of 2007- 2008 (Chalip \& Leyns, 2002; Daniels, Norman, \& Henry, 2004).

Concerning the sailing, the global relevance of the America's Cup and Luna Rossa team pushed this sport to achieve more visibility and more space among the media, the public and the magazines. Sailing is a sport that guarantees a high return of image to the hosting places. Image effects are driven from the mediatic exposure guaranteed to the sponsoring brands and the ability of sailing to build a close affinity with the brand object of the sponsorship. Among the target audience that follows sport on the media and on TV, sailing enjoys an image with solid features characterized by structural and emotional elements. It emerges that sailing emphasizes more and more positive structural elements. It is a healthy, complete, clean, engaging, international sport and suitable for everyone (Gibson, Kaplanidou, \& Kang, 2012, Andersson \& Lundberg, 2013).

In this scenario, the Europa Cup Series 2021 represented the Champions League of sailing. It is a European competition constituted of 10 events in 10 different European countries (Koper, Slovenia; 
Warnemünde, Germany; Dziwnow, Poland; Malmo, Sweden; Lugano, Switzerland; Balatonfüredy, Hungary; Tivat, Montenegro; Hyeres, France; Naples, Italy; Hvar, Croatia) that attracts the attention of several categories of people in Europe and Italy. All the events of the Cup are sailed and organized under a common Notice of Race and standard Sailing Instructions. These events, for Olympic Standard and Radial Women Classes are graded in World Sailing Ranking List and overall, every year for the Europa Cup Trophy.

Table no. 1 The Europa Cup Series 2021

\begin{tabular}{|l|l|l|}
\hline Events & Date 2021 & Venue \\
\hline 1 & May 28 -30 & Koper, Slovenia \\
\hline 2 & July 08 -11 & Warnemünde, Germany \\
\hline 3 & August $20-22$ & Dziwnow, Poland \\
\hline 4 & September $03-05$ & Malmo, Sweden \\
\hline 5 & September $10-12$ & Lugano, Switzerland \\
\hline 6 & September $24-26$ & Balatonfuredy, Hungary \\
\hline 7 & October $07-10$ & Tivat, Montenegro \\
\hline 8 & October $14-17$ & Hyeres, France \\
\hline 9 & October $21-24$ & Naples, Italy \\
\hline 10 & December $28-31$ & Hvar, Croatia \\
\hline
\end{tabular}

The Europa Cup trophy is sailed in Laser Class Boats as recognized by World Sailing commonly sold under the brand name ILCA. ILCA is the International Laser Class Association, while European Region office of ILCA is called EurILCA. The Secretary at office and the Executives are serving the European Districts for the best organization of European events. EurILCA issues the guidelines, the agreement draft, the Notice of race (NOR) and the Sailing Instructions (Sis), takes the responsibilities for secretarial and administrative regulatory aspects linked to the sailors and to the regatta management. EurILCA manages the calendar and entries of each Europa Cup Regatta, publishes NOR, Sis, regatta results, supports the Organization Committee with secretarial and communication services, as well as playing the role of advisor for the consistency of an International Jury. EurILCA executives cannot take any decision regarding local events without involving Local EurILCA District. The Local ILCA District approves the agreement signed by the Organizing Committee, cooperates with the Europa Cup Organizing Committee, refers to the EurILCA Executives for any issue that can affect the success of the event and where an appropriate action taken in time can solve it. The Local ILCA district takes part of the Organizing committee. The Local ILCA District plays the role of facilitator in introducing the EurILCA Representative and the Race Officials at the time of the Event.

In each of 10 events around Europe (Koper, Slovenia; Warnemünde, Germany; Dziwnow, Poland; Malmo, Sweden; Lugano, Switzerland; Balatonfüredy, Hungary; Tivat, Montenegro; Hyeres, France; Naples, Italy; Hvar, Croatia) competitors are divided and scored in the following categories ILCA 7 (overall, under 21, boys under 19) ILCA 6 Women (overall, women under 21, women under 19, girls under 17) ILCA 6 Men (overall, boys under 19, boys under 17) ILCA 4 Boys (overall, boys under 16), ILCA 4 Girls (overall, girls under 16) ILCA 4 (12 - 16 years).

EurILCA final prizes are awarded for the Europa Cup Troply, but prizes are awarded also at each of 10 events at the first 3 places in each overall category and for the first in each subcategory. For the Italian leg of 21-24 October in Naples the MariComLog trophy, offered by the Marina Militare High Seas Academy, is awarded to the overall winner of the largest fleet. 


\section{Organizing authorities}

The Europa Cup Italian race was the only Italian leg of the Europa Cup 2021 in the ILCA class (ex Laser). The event was held from 21 to 24 October in Naples in the Navy military base of Nisida, where crews from 9 countries competed for a total of 300 boys in the race. It was organized by Italian Military Navy, Italian Naval League of Naples, the Real Yacht Club Savoia according with EurILCA, the Italian Laser Class Association (ILCA) and the Italian Sailing Federation (FIV). The Italian Europa Cup race took place from 21st to 24th of October 2021 in Nisida.

Nisida is a small island belonging to the archipelago of the Flegrean islands, located at the extreme offshoot of the Posillipo hill, in the locality of Coroglio. From an administrative point of view, it is part of Bagnoli, a district of the municipality of Naples. Its small port towards Coroglio was used by NATO until its transfer. Until 2012 there was the Allied Maritime Command, which moved to England. The base then returned to Italy and is now the headquarters of the Navy Logistics Command (MARICOMLOG). Nisida is not accessible to the public and connected to the mainland by an artificial dam.

In Nisida the Logistics Command of the Navy (MARICOMLOG) of Military Navy hosted the Italian EurILCA race 2021, organized with the Italian Naval League of Naples (LNINA) and the Real Yacht Club Savoia (RYCCS).

Figure no. 1 Actors and activities

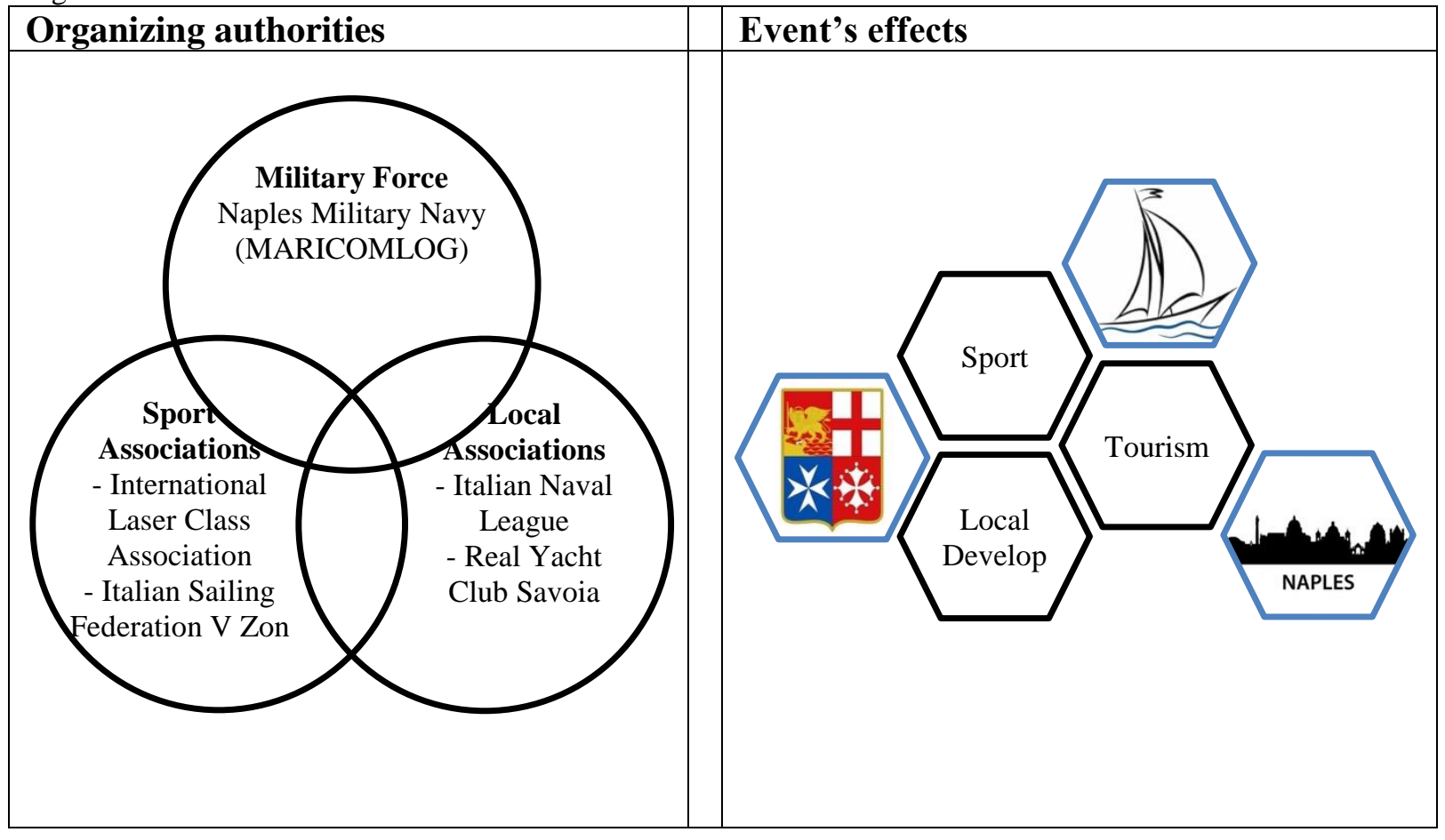

Organizing Committee (MARICOMLOG, the Italian Naval League of Naples and the Real Yacht Club Savoia) is the hosting team that, takes the responsibility of each on-shore and off-shore issues, Jury and Race committee, and local secretary services for the best organization of the regatta. In Naples the Logistics Command of the Navy (MARICOMLOG), Italian Naval League of Naples (LNINA) and Real Yacht Club Savoia (RYCCS) worked together, but with different missions and roles, for realizing the Italian race of EurILCA 2021.

The Europa Cup race of Naples 2021 was organized by Italian Military Navy for promoting the navy values, offering a service of high social value for families, promoting the diffusion of the concept of sport as an instrument of personal and collective growth, diffuse 
the love and respect for the sea. The competition that saw on the start line over 300 athletes was dedicated to people aged between 12 and 30 who braved the waters.

The Logistics Command of the Navy, MARICOMLOG, is the High Command of the Italian Navy able to manage the logistical needs of the armed force. MARICOMLOG was established following the reorganization of the Navy, when the Inspectorate for Logistic Support and Lighthouses (NAVISPELOG), was reconfigured into the Navy Logistics Command from 30 April 2013. It maintained the same organizational structure by incorporating the Logistics Department and Infrastructure Department of the Navy General Staff, to group under a single Command the responsibility for maintaining the efficiency of the naval and ground component and maritime signaling, as well as the acquisition of goods and services for the entire Navy. It is qualified as one of the three Central Commands of the Navy, together with the Operational Command of Rome and of the Training in Ancona. The Maritime Commands of the North, South, Sicily and the Capital depend on the Logistics Command of the Navy for logistical tasks and functions and on the Navy Chief of Staff for territorial tasks and functions. From 1 November 2013, the Logistics Command was transferred from Rome to Naples and at the same time the Headlights and Signaling Department was established, which after initially maintaining its headquarters in Rome, starting from 15 March 2014 was transferred to Naples in Nisida base.

The Italian Naval League is a public organization that operates under the supervision of the ministries of Defense and Transport and Navigation. It aims to diffuse among Italian people the love for the sea and the knowledge of maritime problems. The Italian Naval League protects of the marine environment and promotes cultural, naturalistic, sporting, and educational initiatives tied to sea. The Italian Naval League also works in concert with central and peripheral public administrations, with CONI and the Naval Maritime Leagues. The Naval League of Naples works to spread the love for the sea, in a city that has one of its most significant leitmotifs in the sea. The members of the Naval League of Naples are over 1.000 and the fleet of social sailing and motorboats reaches 80 units.

Real Yacht Club Savoia (RYCCS) was founded on 15 July 1893 by eleven members of the Circolo Canottieri Italia who, by mutual agreement, break away from the adjacent redblue partnership founded four years before and thus constitute a competitive alternative to their old club with the new white-light blue colors. Umberto I and the heir to the throne Vittorio Emanuele, Prince of Naples, ensure that the club gains high prestige. Thus the members of Canottieri Sebezia change the name of the Club by inserting the name Savoia and, to remember their missing friends, they replace the light blue color of the shirt with black. During the ' 80 the Savoy suffered from a crisis that seems irreversible to most, the number of members more than halved and sports and social activities reduced to a flicker. In the ' 90 the Savoia circle resumes living. The old rules of social life never codified by the club's constitution and by-laws are dusted off. We always dine with a jacket and tie in both summer and winter, mobile phones strictly off and the ladies always accompanied, especially at the restaurant, the policy stubbornly kept out of the club. Today the Club has members included at the highest levels of political, scientific, industrial, amateur, artistic, and not only national life. The sporting successes of the Club are flanked every day by social events that make Savoia one of the most prestigious center of cultural and social life in Naples.

Italian Sailing Federation - FIV replaces institutions which, from 1879 to now, have been national authorities of Italian sailing at the IYRU (International Yacht Racing Club, founded in London in 1907). The birth of the sailing sport in Italy dates back to 1852 when, on the initiative of the Marquis Ludovico Trotti, the "Regatta Club" was founded on the lake Como. On 1 January 1879 the Regio Yacht Club Italiano (RYCI or Italian Royal Yacht Club) was founded in Genoa (it remained active until 1912) and on 8 August 1880 the first national race La Spezia is run with the participation of nearly 177 crews. Between 1913 and 1918, on 
the initiative of the RYCI, the Unione Nazionale della Marina da Diporto (UNMD or National Union of Recreational Marinas) was created to "coordinate and regulate the activities of sailing clubs". The UNMD was transformed in 1919 into the Italian Royal Yacht Club. In 1927 the CONI recognised the RYCI and changes its name in 1928 to the Federazione Italiana Vela (FIV or Italian Sailing Federation). In 1933 the FIV assumed the new name of the Regia Federazione Italiana della Vela (RFIV or Royal Italian Sailing Federation) and it moved its headquarters to Rome. In the postwar period, on 25 April 1946, the Regency Council was elected in Rome, which, on 16 November 1946, proclaimed the National congress of sailing societies in Florence. The Congress formed the Unione Società Veliche Italiane (USVI or Italian Union of Sailing Societies), bringing the organisation's head office to Genoa (Duca degli Abruzzi port). Finally, on 5 December 1964 the USVI returned to the old times recovering the name of Italian Sailing Federation (FIV).

\section{Event's effects}

The Italian race of Europa Cup 2021 hosed the best European sailors of ILCA (International Laser Class Association). The island of Nisida hosted regattas for four days, for a maximum of eight races for each fleet, simultaneously on two regatta courses. Collateral events and activities were organized to show Naples' most beautiful places with the aim to combe sport and tourism. It was the first time that the Europa Cup was hosted in Naples. About 300 sailors took part at the event. The Neapolitan was the race with the highest number sailors of all the 10 events, surpassing even that of Hyères and equaling the number of sailors of the Europa Cup Italy 2019 held on Lake of Garda in pre-Covid period. The high number of participants asked for an impressive organizational machine to guarantee the perfect performance. Participants came from many European countries such as Malta, Greece, England, Croatia, San Marino, Finland, Switzerland, Italy. In addition, a delegation from Singapore was welcomed.

The event highlighted how the City of Naples has always been inextricably linked to the maritime traditions and how the Military Navy is able to support the development of city in which it operates. This event highlighted the link between the city, the Navy and sailing, which in turn are synonyms of navy culture, values, and maritime vocation. Naples with its organizational capacity confirmed to be an Italian capital of sailing. Since from the 1960 Olympics, the city is likely to organize sporting events. In one nautical mile, from Molosiglio to Santa Lucia and Posillipo there are 8 social clubs involved in nautical sports.

The Italian Navy, in synergy with the Naval League of Naples, the Savoia Club and with the Italian Sailing Federation, managed the event to offer to Naples an opportunity to show its beauty landscape, cultural wealth and great sailing tradition all around the world.

The Europa Cup race in Nisida offered a great opportunity to strengthen the restart of the sailing organization of the territory. With this regatta, the international profile of Naples was strengthened in the panorama of major sporting events linked to the sea and a strong signal was transmitted for the new challenges of the Olympic four-year period. Nisida gave value to this international event, evidencing to be a good scenario for other major events. This event could be the first of many other international events in which Italy can show its beauties to foreigners.

According to Giuseppe Abbamonte, Logistics Commander of the Military Navy, this event one side led boys to be closer to navy value, on the other exposed Naples' beauties to all the world. The Commander also evidenced his satisfaction in showing how Military Navy can cooperate with other organizations in supporting economic, touristic, and cultural development of local communities and places.

\section{References}


Andersson, T. D., \& Lundberg, E. (2013). Commensurability and sustainability: Triple impact assessments of a tourism event. Tourism management, 37, 99-109.

Chalip, L., \& Leyns, A. (2002). Local business leveraging of a sport event: Managing an event for economic benefit. Journal of Sport Management, 16(2), 132-158.

Daniels, M. J., Norman, W. C., \& Henry, M. S. (2004). Estimating income effects of a sport tourism event. Annals of tourism research, 31(1), 180-199.

Gibson, H. J., Kaplanidou, K., \& Kang, S. J. (2012). Small-scale event sport tourism: A case study in sustainable tourism. Sport management review, 15(2), 160-170.

Kaplanidou, K., \& Vogt, C. (2007). The interrelationship between sport event and destination image and sport tourists' behaviours. Journal of Sport \& Tourism, 12(3-4), 183-206.

Weaver, D. B., \& Lawton, L. J. (2013). Resident perceptions of a contentious tourism event. Tourism Management, 37, 165-175. 